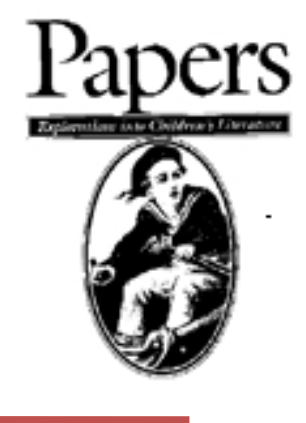

Books or Toys? A Traveller's Tale:

\title{
Researching Early Movable Books for and by Children in Material and Virtual Collections
}

\author{
Jacqueline Reid-Walsh \\ Pennsylvania State University
}

A number of years ago, I first experienced the thrill of gaining access to the Bodleian Library at Oxford University and being granted permission to see some of the books that compose the famous Opie Collection. This joy as I sat in the New Bodleian Reading room was compounded when the Head of the Special Collections Clive Hurst, upon being told my interest in early children's literature and culture, brought by an exquisite, little thin mid- $18^{\text {th }}$ century volume. When he opened it up it revealed a story of words and etched pictures about a set of characters called Harlequin, Columbine, and Clown that proceeded by means of flaps that could be lifted up and down, the directions for use sometimes being set in the verse or printed on top of the picture. He looked at me and said, 'Are these books or toys?'

I immediately realized that not only did I not recognize the characters and plot but also that I did not even know how to examine it. Was I to read the words and then turn the images up and down? Was it the opposite? What was the order of looking and reading? Did I look at the top half first or the bottom? What was the order horizontally? Since it consisted of several accordion folds, was it read like a strip or like a book? What were these artifacts anyway? How would they be classified? Requiring active engagement by the reader-viewer, much like a puzzle or game with more than one solution, they were more than a story and a picture combined (like a picture book). Were these even intended for children?

This moment in the Bodleian and the attempt to answer Clive Hurst's provocative question about these little known flap books has engrossed me. The question has been at the forefront of my thinking as I have set out on physical and virtual travels amongst rare books collections in England, the United States and Canada looking for other examples of flap books. In so doing, I have become fascinated by other early movable books created for children, well before the invention of the "stand-up" in the Victorian period, such as the paper doll book and the toy theatre. I have equally become engrossed by how these were not only produced by commercial printers in these periods but were also modified and made by children as early instances of Do-it-yourself or DIY culture. 
My travels are far from over. I have not been able to visit physically all the repositories; the ones I have already visited have acquired new books; and as is always the case, each instance of additional research generates new questions that take me back to collections I had thought I was finished seeing.

Because of their nature, finding movable books involves certain challenges. Movable books are an ancient form, predating the invention of printing in the West and defined as illustrated codexes (the format used in modern books) with mechanical parts such as a flap, tab, slot, wheel, or pop-up (McGrath 2002, pp. 5, 7). To 'read' a movable book, a person has to engage with it in several ways: reading the words, as in a story, looking at the images, as in a picture book, and moving the components, as in a game. In each case, the moveable parts depict change or movement that is effected by the reader-viewer-player or 'interactor' (Murray 1997, pp. 78-79; Reid-Walsh 2012).

Despite their long history and innovative design, the place of movable books in histories of AngloAmerican children's literature is on the margins because the narratives tend to be minimal and rarely of purely literary interest. If they are discussed, they tend to be placed in a side chapter as novelties or knick-knacks (Muir 1954). If studied, they are usually approached as a subset of the picture book (Arizpe \& Styles 2003). For the most part, they tend to be studied by collectors and curators (Haining 1979; Montanaro 1993; McGrath 2002) although discussion is emerging in recent historical surveys of children's literature (Grenby \& Immel 2009). Some scholars, such as Eric Faden (2007), of late $19^{\text {th }}$ century visual culture and early cinema have studied elaborate movable books made possible by developments in paper engineering but have less interest in the earlier, simpler types.

I include in my investigation not only commercially produced print objects but child-made objects. Considering these homemade productions as juvenilia, in most cases by anonymous and 'nonfamous' children, provides documentation of how children engaged with the movable books to the extent of making their own. They provide material evidence of use, complementing other evidence such as inscriptions and marginalia employed by historians of children's literature (Grenby 2011). They are also important in their own right as manuscripts revealing insights into certain children's lives (similar to Andrea Immel's 2005 study of one $18^{\text {th }}$ century child's scrapbook) and the culture in which they were made.

In all cases, early movable books are not easy to locate in library collections. This occurs for a number of reasons. These include there being no standard all- encompassing bibliographic term, that a number of different types exist, and that circumstances of their production (whether they are commercially or home produced) effect their placement in libraries. This essay is part of an ongoing project to draw attention to early movable books for and by children as an important area of research in children's literature and culture. The aims are to describe my experiences researching some of the main repositories of early movable books I have visited physically or online. This is not a survey but a personal narrative, based on my ongoing physical and virtual travels to university based research libraries and public institutions. I consider the process of doing research in each locale and consider the 'affordances' (Gibson 1977, pp. 127-143) or what structural and literal 
supports and constraints I have experienced. I begin by briefly describing my research experiences in material collections of early movable books in libraries and museums in England, the United States and Canada. Then I discuss a number of main repositories of media reproductions, increasingly now in digital format, that I have consulted. I organize my discussion in terms of researcher issues and challenges. In each realm, my controlling question about the definition of movable books stems from their hybrid nature: part book, part toy or game and part print (Hurst 1995). This in turn leads to the ambiguous classification of movable books in repositories.

In what follows, I take the reader on a journey to different material and virtual libraries. There are parallel journeys here: my account is a journey of discovery of what research into early movable books tells us about children's texts of the past. It is also a discussion about research today in special collections of children's materials. In my account, I employ the analogy of my travels being a kind of ethnographic research (indeed early ethnographers were often travellers) into the strange and 'exotic' culture of rare books collections, with their own special rules, codes of behaviour, gatekeepers, and guardians or curators. To enter these places, I have to seek to understand this culture on its own terms and to engage in special activities or rites of passage. My adventures are a travelogue that shows me moving from being an uninitiated 'outsider' to a sometime 'insider' who can navigate the terrain more comfortably. My narrative is a guide for others who are interested in entering this domain.

This notion is inspired partly by the idea of 'archival ethnography' (Gracey 2006, p. 335) where a researcher enters a field to gather information by becoming immersed in a community, and by engaging with its members in order to "identify, analyze and articulate the "insider" (emic) perspective' (Gracey 2006, p. 336). Yet, I do not enter a library to engage in participant observation, in-depth interviews, or focus groups with librarians or other researchers. Rather, by telling my travel tale in first person voice, the narrative is a kind of autoethnography. Autoethnography is defined as a form of qualitative research that uses the autobiographical experiences of the researcher as a means to understand the self in connection to others (Chang 2008, p. 56; cited in Donaldson-Randall 2011, p. 13). Since autoethnography is a self-reflective form of analysis, a third journey I engage in is one of self-discovery.

\section{Material Collections}

By definition, a library collection, like any collection, is made of materials taken out of the original context of use and situated in another one (Arendt 1969, pp. 42, 54). Therefore I think about engaging with early movable books in two collecting contexts: the original collector who obtained the objects and the collecting practices engaged in by the curators of the repositories. This occurs on both the large and small scale.

There are numerous comprehensive special collections of early children's materials that have extensive holdings of movable books. Many specialize in the spectacular Victorian productions (such as the Baldwin library in Florida and the University of Virginia) but some contain a wide range of types dating back to the $18^{\text {th }}$ century and before, such as the Elizabeth Ball collection in the 
Lilly Library, at Indiana University, Bloomington Indiana. It has almost forty harlequinades, and is on my 'to visit' list. I know several collections quite well: the Opie Collection at the Bodleian Library, the Victoria and Albert Library, the Osborne Collection, which is part of the Toronto Public Library, and the Cotsen Collection at Princeton. Notably, the latter includes an extensive collection of both early movable books and a number of child-made manuscripts, particularly of flap books. Other early movable books and related artifacts are housed in other specialist collections based around genre, such as ephemera in the John Johnson Collection at the Bodleian Library, the toy theatre collection forming part of the Theatre Collections at the Victoria and Albert museum, and the Prints and Drawings study room of the British Museum. In the next section I consider how I engage in research in these superb material repositories.

\section{Researcher Challenges: The Process of Engaging in Research in a Rare Books Library}

\section{Catalogue literacy}

The first challenge in researching early movable books stems from their hybrid nature, for they may be housed in different types of repositories reflecting whether they are considered to be a book, a toy, or a print object. If housed in a library these items may be classified in various ways. If not commercially produced, but homemade, they are catalogued as manuscripts. If classified as a print, such as is the case with secular flap books or harlequinades (O'Connell 1999, p. 36), they are not considered a book at all so may be housed in a museum in a popular print collection.

As Alberto Manguel observes, ideally a catalogue (paper or online) is the 'map' of a library (2010, p. 268). This is in flux, for new acquisitions need to be documented before they are listed. Since the catalogue is the main access point, I have found it is important to acquire the skills to read it properly, this skill being a type of literacy in itself.

When searching the online or original paper card catalogues it important to realize that movable books may be classified generically as movable books or toy books, and the individual types may be classified by their format such as paper doll books, toy theatres (also called Juvenile Drama), pop-up books and so on. They may also be classified by their components as is sometimes the case with toy theatres that are listed by their parts, such as character sheets, scenes, stages, and scripts. Flap books are complicated to find since they may be called by their earlier term 'turn-up' or by the antiquarian term 'harlequinade' (Richards 2000, pp. 145, 171). They may also be referred to as 'metamorphic pictures' such as in the list of genre terms established for bibliographers set out by the Rare Books and Manuscript Section (RBMS) of the American Library Association (http://www.rbms.info/committees/bibliographic_standards/controlled_vocabularies/genre/tr540.ht

$\underline{m})$. Although this is complicated for a non-librarian, I have found it is necessary to engage in as much preparation as possible so as to not waste your time and the librarian's time when you enter the repository. 


\section{Gaining access}

Having performed this preliminary sorting, the next stage is to gain access to the repository. Like a separate world or culture, a rare books room may have complex and arcane rules, including requiring letters of introduction. I always try to contact the librarian or curator in advance to obtain permission to see the materials. This is especially critical since little used materials are sometimes stored off site and may take time to be collected (this may happen at big repositories such as the British Library, the New Bodleian library since they are being renovated until 2015, or the University of California in Los Angeles, the UCLA library). As well, you may also obtain a consultation about the objects, crucial reference materials and contextual material that only are available in their library. If you can demonstrate you are a serious scholar, curators are more inclined to share some of their vast knowledge with you. In this way I have had the good fortune of learning first hand from some most knowledgeable curators at the Bodleian, the British Library, the Houghton at Harvard, the Cotsen Collection at Princeton, the Osborne Collection in Toronto, and at McGill University. As well as having extensive knowledge about the history and material property of the object, they can provide a wealth of secondary reference materials. For instance, when examining a 1654 religious flap book with the print curator at the Houghton Library at Harvard University, she showed me the notes taken by the Harvard curator who obtained the object in the 1950s, containing his insights about the links to the earlier British text.

Subsequent to my initial visits, several curators have become Lockian mentors guiding me in my journey learning about the intersections between rare books, book history and early children's materials. True to Locke's spirit of learning as play, I have on occasion played with a curator. At the Fisher Rare books Library at the University of Toronto, I once had the opportunity to play with a fully set up and mounted toy theatre play consisting of a miniature wooden theatre complete with stage, scenes, wings, and characters mounted on metal slides so they could be moved around. The experience of pushing the metal slides around the stage and clashing them together in combat scenes was both thrilling to participate in but also provided me with an important research insight. It made me appreciate how interactive the engagement was for the young boy players who were the intended audience, and how the toy theatres could be understood as a precursor of some computer games today (Reid-Walsh 2008). On the other hand, on occasions when I have not been fully prepared, I have received the opposite treatment. Chastened and chagrined, I have learned by experience to prepare for a rare books visit as if it were a graduate school oral exam!

\section{Entering and working in a rare books room}

Requirements upon entering the library vary widely. In most instances, I lock up all my belongings and bring only a pencil and paper, perhaps a computer and a camera. Again, I have found it is best to discover these regulations ahead of time. The opportunity to touch the books varies. At one extreme, with exceptionally fragile and restricted objects, they were presented in a protective covering allowing me only to gaze at the book not read it in total. If the object is able to be touched, there may be a surveyor watching you and you are provided with the following props - a book support, a fabric snake to keep the fragile pages open, a pair of white gloves and a ruler. You may 
be able to see only one object at a time or several at once to compare. Ideally, I like to play with the movable book and experience the object with several senses - sight, touch, smell, movement - to realize the dimensional aspects of size, shape and interactivity.

I have discovered that gaining access through justifying the need to view the materials, and sometimes proceeding through elaborate protocols, is a small investment for the unlimited value gained. Some libraries such as at the Bodleian, the British Library, and the Library Company of Philadelphia that house the originals may use reproductions as a gate-keeping device to screen users to ascertain if access to the originals is necessary. This may include a paper facsimile of the fragile object (such as an early American Metamorphosis flap book) that is fragile in itself but shows the three-dimensionality and interactive capability of the artifact. Or a librarian may employ a media reproduction to screen users, such as at the Bodleian Library using the microfiche of the Opie Collection or at the British Museum using the microfilm of the Thomason Tracts. For someone like myself who needs access to the original to gain multi-sensorial information, it may be necessary to first work through these substitute items and then make a case for seeing the original.

\section{Working in large collections: Original collecting context}

Studying a large collection is always illuminating. For example, at the Blythe House repository of the Victoria and Albert Museum the vast holdings enabled me to trace a production history of the toy theatre in England by being able to see the corpus of William West, who is one of or the earliest printer. The collection includes his first play-book The Secret Mine (1811) with handwritten script and fold out, coloured illustrations for the scenes and characters . Examining this exquisite object gave me an insight into the creativity and imaginative genius whereby a toy theatre printer adapted a contemporary stage hit onto the medium of the small, paper page, a good example of a cross-over text now associated with film adaptations.

Working in these repositories has also enabled me to experience the material context of an object in its original collecting context. This may provide insights into earlier curatorial practices. For instance, when a major toy theatre collection was obtained

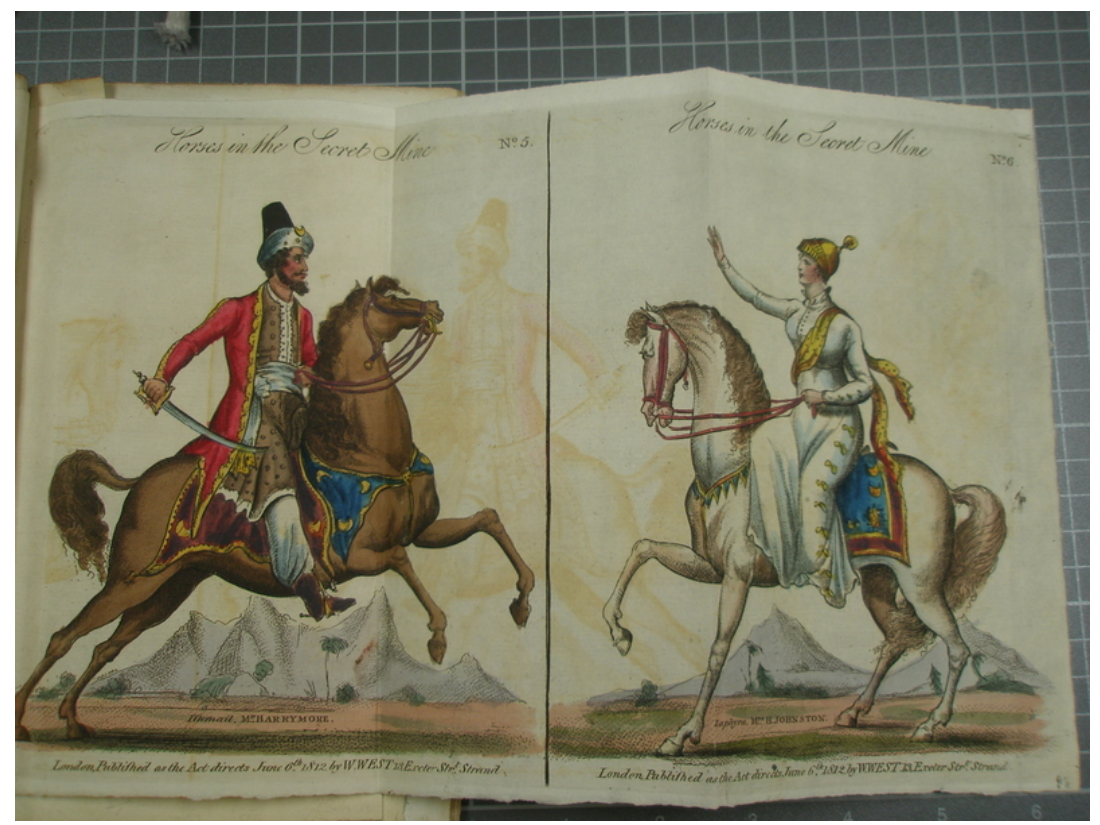

Figure 1. Secret Mine (1811, p.11) Victoria and Albert Museum

by the print room in the British Museum some years ago (O'Connell 1989, p. 37), the curatorial staff took apart the original into its components of separate sheets of scenes, wings, characters and pasted each into gigantic volumes dated, numbered and with annotations. Each sheet is presented as 
separate print. This disassembling of an artifact would not be engaged in now, but the components are preserved. Together the scenery, staging, and characters in various costumes and poses provide important evidence of the staging and presentation of Regency and Early Victorian popular drama. Otherwise, this information would be gone since the sets, costumes and in some case theatre buildings have been lost or destroyed.

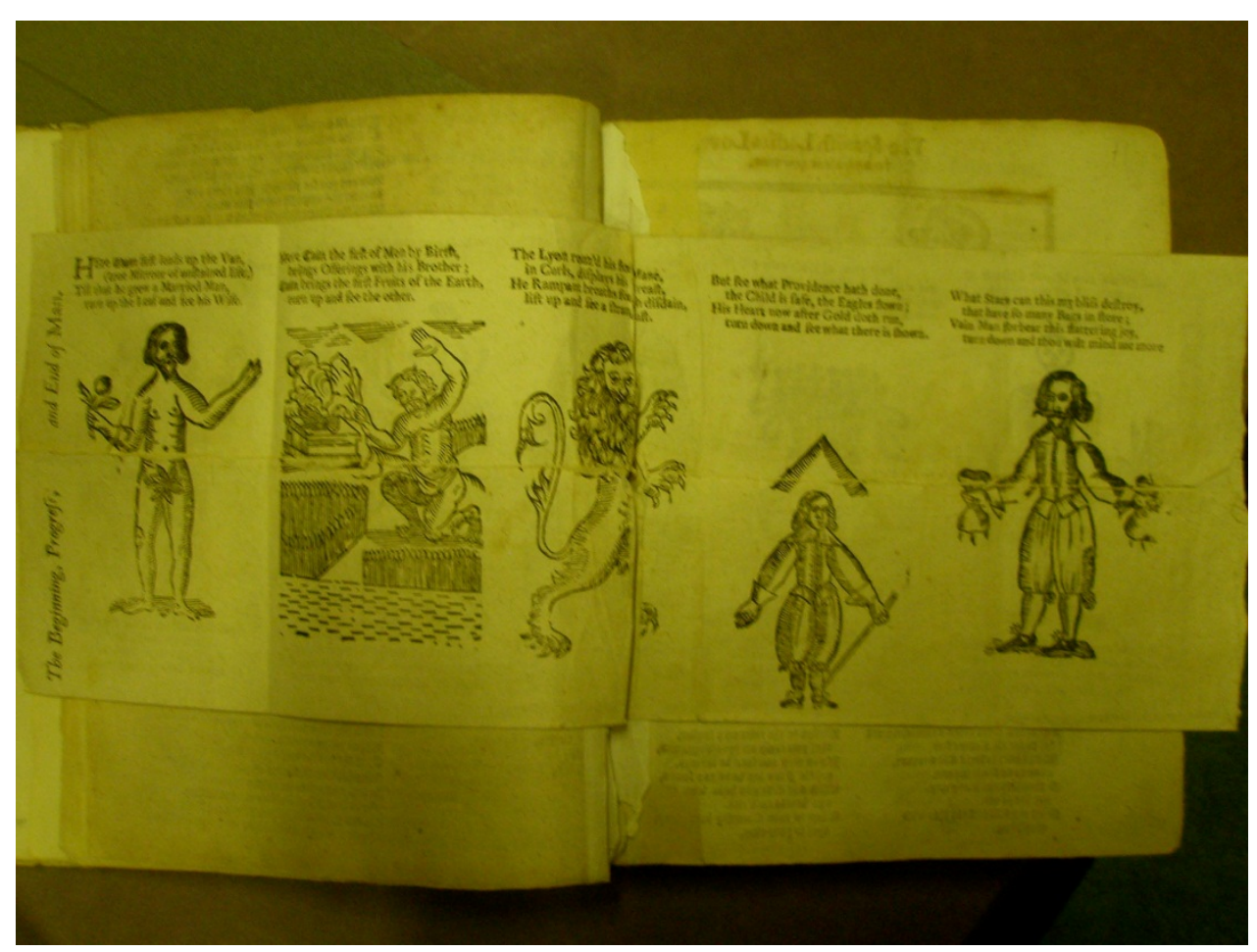

Being able to appreciate the original collecting context may span hundreds of years since an object may be preserved in its state of being received. I have experienced the thrill of appreciating how a contemporaneous collector engaged with an object, indicating the initial reception and context (McKenzie 1999, pp. 11-13). Here,

Figure 2. The Beginning, Progress and End (1688, p.12), Bodleian library, also available at http://theconveyor.wordpress.com/2009/10/08/cain-inthe-canefields/

engaging with the object is like opening a time capsule, transporting me back to an earlier period. For example, concerning my research into early religious flap books, the earliest known copy of The Beginning, Progress and End of Man (1650) is housed at the British Library (see Figure 2). A restricted document, seen only with careful screening, it is pasted into a large folio of tracts and broadsides compiled by George Thomason (d. 1666) a Royalist bookseller in London who collected over 23,000 ephemeral documents about the Civil War and Commonwealth (O'Connell 1999, pp. 192-194). The material context for the tiny uncut flap book are large broadsheets of words and images containing first hand information about the execution of Charles I, the ascension of Cromwell and so on. These give a particular political significance to the conventional images of the flap book, particularly the lion that has a head that resembles Charles I. Another early edition of the same text (1688) is housed at the Bodleian Library. It is also uncut and pasted into a large volume of illustrated ballads collected by Anthony á Wood (1632-1695) an Oxford Antiquarian (O’Connell 1999, p. 194). This material context throws new light on the lines of the verses, which are in ballad form.

These examples highlight the first hand learning only possible when using a collection in the physical space of rare books library. When travelling to these locations and entering the space as a 'reader' I become a temporary member of a special culture that combines concern for the books as 
objects to be cared for with research support. In these locations, 'reading' is a weak term. By suggesting only the value of sight it neglects the multisensorial engagement only possible when interacting with the artifact. In contrast to working in material collections, I also engage with virtual collections. In the next section I discuss some challenges that I have encountered in these spaces.

\section{Virtual Collections}

I use the term virtual collections to refer to media reproduced archives, digital reproductions being an extension into newer formats of older practices. Other modes include microfiche and microcard that provide photographs of the objects and are durable, often available in a number of research libraries outside of the host institution (such as the microfiche of the Opie Collection) but often unwieldly to use. Digital reproductions, if made available on the Internet, may be accessed by multiple users at once and by users located in many geographically dispersed locations. I have found this to be a tremendous asset. Instead of having to travel physically to a rare books library, I simply sit with a computer hooked up to internet access and travel virtually. For example, instead of having to travel to the Bodleian library to see their 1688/89 religious flap book (Figure 2), I can simply go to their rare books blog at http://theconveyor.wordpress.com/2009/10/08/cain-in-thecanefields/. For me, the main issues and challenges with virtual collections are (apparent) ease of access and partial experience of the artifact.

\section{Virtual access: Monetary gate-keeping}

The idea ${ }^{1}$ of effortless virtual travel when sitting with a computer is somewhat of a ruse, for there are many types of virtual collections, some requiring paid subscriptions and others free. This difference reminds me of the contrast between the $19^{\text {th }}$ century circulating library restricted to gentlefolk or those with means, and the $20^{\text {th }}$ century public library open to all. For the former, being able to access a collection is dependent on an institution paying the hook-up fee. It is a type of monetary gate-keeping device. For example, the main online entry point to the John Johnson Collection of Ephemera at the Bodleian Library (a library which anyone can enter if providing

sufficient rationale) for Canadian and American users is at http://johnjohnson.chadwyck.com/marketing.do. If your university or public library does not belong, you cannot see these materials which include important contextual materials about early movable books such as period board games, theatre posters and decorated writing sheets, and a child made flap book. This is immensely frustrating since you are excited to see these materials but blocked from the outset.

Other sites where the gate-keeping to virtual travellers is monetary are comprehensive, publisherfinanced sites culling materials from many libraries worldwide. I have found two useful comprehensive online collections containing a broad cross-section of early movable books. One is 'Early English Books Online' or EEBO, which has digital facsimiles of the earliest known flap books from the 17th and 18th centuries housed at the Bodleian Library, the British Library and the Houghton Library at Harvard at http://eebo.chadwyck.com/home. A counterpart for the earliest movable books published in America is 'Early American Imprints' is at 
http://www.readex.com/readex/product.cfm?product=247. These collections are full-text, and searchable by title and category. At the same time, the viewing experience is partial. With the flap books, for example, the words are difficult to read, the images hard to see and although the black and white images show different views of the artifact with flaps open and shut, the total narrative difficult to ascertain.

\section{Free virtual access}

The second type of online collection of early movable books is freely available online. There are ongoing global initiatives that directly address open access. For example, there is the massive cross institution and cross nation initiative of the World Digital Library http:/www.wdl.org/ that has partners such as UNESCO, the American Library of Congress, many other national libraries with partial funding from Google (Manguel 2010, p. 284).

In my experience, most freely accessible collections are hosted by individual libraries. They may not be permanently available due to technical issues or if they form part of a temporary exhibition. These sites tend to be of two types: comprehensive digitization projects and smaller, virtual catalogues. To date, most libraries digitize their own collections of movable books, focusing on the later $19^{\text {th }}$ century spectacular types. For example, there is a site hosted by the University of North Texas called 'Pop-up and movable books: a tour through their history' at http://www.library.unt.edu/rarebooks/exhibits/popup2/. Based on their Weaver collection, this site provides a brief history of the ancient form and consists of fine range of English, European and American examples. Interestingly, the site has animated images that show the mobility of the artifacts and allows some limited interactive engagement. The only pre-1850 examples are the S. and J. Fuller Paper doll books. Here I can click on the doll and play virtual dress-up although I cannot access the story.

Another comprehensive ongoing digitization project is located at the University of Florida Baldwin Library of Historical Children's Literature at http://ufdc.ufl.edu/juv. The site is searchable in several ways, including full text. The category "toy and movable books" brings up 18 items with thumbnail images including a facsimile of Pilgrim's Progress (1819) as a flap book.

Increasingly, collaborations are beginning to occur between one library housing the material collection and another hosting a digital project. One comprehensive resource is the Hockliffe Project at De Montfort University, England, which has an excellent collection of early children's materials including early movable books and essays by a leading scholar Matthew Grenby. While De Montfort hosts the website, the physical collection is housed in the Polhill Library, University of Bedfordshire. Again the layout of the images makes viewing and reading difficult ${ }^{1}$.

While I have found these impressive, large scale projects give a sense of what a library collection contains and thereby serve as a virtual map or index, other libraries employ online display catalogues that provide more a taste or sample of their holdings. One charming, digital catalogue based on a material and digital exhibit focusing on later movable books is the University of 
Virginia's Brenda Forman collection of pop-up and mechanical books. Called 'Pop Goes the Page' at http://www2.lib.virginia.edu/exhibits/popup/theme.html.

There are also presentations of contextual print culture and optical toys on virtual display. Moving images and the ability to click and rotate provides a sense of motion and three-dimensionality, so I have found there is progress towards multi-sensorial effects but no interactivity.

Another engaging example is hosted by the Osborne Collection of early Children's Books is part of the Toronto Public Library in Canada. This is an online exhibit accompanying a material display called 'This Magical Book: movable books for children, 1771-2001' at http://ve.torontopubliclibrary.ca/magicbook/home.html. The website includes moving facsimiles of a number of complicated movable books with brief pop-up bibliographical notations. It is both a supplement to the paper catalogue of the exhibit by Leslie McGrath (2002) by that name and a peep into the range of the material collection. When I click on a picture, a three dimensional photo is set in motion. Examples include peepshows, volvelles, and pop-ups from 1825 to 1950. The site also includes sound files with the lion image from Lothar Meggendorfer's mechanical book Always jolly! A Movable Toybook [1891?] so the experience is bimodal. Unfortunately, the presentation remains a virtual show.

\section{Working with virtual collections}

I have found the experience of working with virtual collections to be in many ways opposite to working with material collections. With material collections, obtaining access may be complex, laborious and even arcane but once you are in the library, you become a temporary member of their community, and engagement with the objects is assured. By contrast, when working online the most compelling issues and challenges are the (apparent) ease of access on the one hand, but a partial sensory experience on the other. Unlike in a physical library, your research is done in isolation.

Of course all digital collections are subject to the same concerns endemic to any Internet based resource such as power outages, the stability of servers and other technical issues. Nor is there any guarantee that a repository, however excellent a resource, will continue to exist. For example, my favourite digital collection of theatrical materials, 'People Play UK' of the Victoria and Albert Museum included interactive images of toy theatre special effects (precursor of special effects in films today) so when you clicked on a pantomime stage set complete with wall, it would collapse. It was permanently shut down for technical reasons.

With virtual collections generally, what is most disappointing is the absence of multi-sensory engagement with the texts, only possible when you are engaging with the physical objects. Showing the possibilities of interacting with early movable books remains a challenge. Again, new technology is changing this. I am involved with developing an exhibit site using collections shared by several libraries, notably the Cotsen Library, Princeton based at the Pennsylvania State University Library. The aim is to take digital facsimiles of early movable books, beginning with both commercially produced and child made flap books because they are the simplest and most 
transparent in design, animating them, and making them accessible by 'virtual touch'. This is achieved through using a gaming engine platform that captures the three-dimensionality, interactivity and playability of a movable book by enabling a viewer to activate the book by clicking a mouse or touching a screen. We seek to turn the images into a full-scale digital surrogate of the original, not a flat copy. Hopefully, by appealing to multiple senses - sight, touch, and motion -- a type of virtual synesthesia in the original meaning of sensuous union will occur for the viewer-reader-player. Thereby, virtual play will more closely approximate physical play with the objects $^{2}$.

\section{Conclusion: Researching Material and Digital Collections of Early Movable Books}

One way I understand the relationship between researching material and virtual collections is contained in two metaphors for the book used in book history. One is the idea of a book as an object, analogously to the literary belief in Formalist criticism whereby a book is considered to be a self-contained, wrought artifact. The other considers the book as a text, analogously to literary theories drawn from structuralism and post structuralism, and assumes that the book is a woven text that may exist in any constructed form (McKenzie 1999, pp.13-15). In each of these, the reader has different roles ranging from that of expert interpreter to any person who brings an inert object to life by the act of reading.

These different conceptions of the nature of a book may parallel the differences between the physical and virtual spaces that house book collections. A physical repository houses an object, but it may be so fragile, that while you can appreciate it as an artifact you cannot read it. In contrast, a virtual repository houses a text that you can read, but due to the limited engagement possible, often the sense of the artifact as object is lost.

I consider these metaphors not to be contraries but different ways of understanding a book. Both approaches need to be utilized. Books are material objects with certain properties that can be studied in terms of their production, the methods of manufacture, and how they are received. Bibliography, in the last few decades, has expanded to include the second concept so the field has moved from focusing only on the technical processes of transmission to include social processes. These includes social, economic, political aims of publication, how the books were written and read in the first instance, and how they revised and rewritten. Thereby, researchers can engage in a full study of the production, transmission and consumption of a book (McKenzie 1999, pp. 11-13).

Engaging in this type of project is daunting, but I have found that accessing both a material library and a virtual repository can help. A scholar needs both direct and extended acquaintance with the object as well as contextual information. For example, I have been able to travel to two libraries, Cambridge University and the University of California Los Angeles, on the trail of early flap books that might have been miscatalogued or ambiguously catalogued. I based this decision on a critical reading of the online world catalogue entries. In both cases, my hunches paid off and I have found two more English religious flap books that have not been noted as such by experts. This is only possible by a combination of virtual and material travel. 
Another example of needing both types of collections occurs when the object is so fragile that it curtails the physical engagement a researcher can safely perform, or when the researcher has only limited time to transcribe the words, describe the images, and note the marginal writing. For example, I found in trying to read the owner's inscriptions on paper doll books or translate German versions of a religious flap book called the Metamorphosis it was more done easily online. When working with the physical object, I could safely hold a magnifying glass over a fragile artifact and carefully turn it around. But when the same words appear on a screen, I can safely zoom in, upturn the image, and examine it safely and repeatedly from different angles. I can also go back repeatedly to study the words and images -- use and reuse it without destroying it. If there is a good-sized digital archive, it is also possible to compare the appearance, dimensions, wording, and marginalia across a number of examples.

I think it is important for $21^{\text {st }}$ century researchers to use both types of collections, material and virtual, intelligently and responsibly. In bibliography theory, there are three stages in books that have survived: creation and initial reception, when the book performs the function to which it was intended, a second stage when it comes to rest, and the third when "it is discovered that the book is desirable as an object, either in its own right, or because of the text that it contains. It documents the age that brought it into existence and thus enters the world of collecting and scholarly research" (Adams and Barker 1993, p. 32, cited in Paul 2011, pp. 39-40). Both types of repositories are invaluable to my scholarly recovery project around early movable books. Being able to travel to and work in both material and digital repositories enables scholars such as myself to continue on these exciting adventures.

\section{Coda: autoethnographic reflections of a library traveller}

Nothing replaces the exhilaration of reading rare books in the physical and metaphysical space of an old, beautiful library complete with carved ceilings, beautiful light, solid tables and expert staff. I have experienced this at the Houghton Library at Harvard, the prints room at the British Library, the library at the Victoria and Albert Museum in Kensington, and particularly the 500 year-old Duke Humphrey's library at Oxford. This magnificent building has exquisite wooden ceilings, walls with paintings of Renaissance scholars and patrons, and books that were once chained but now protected by sensors that scream if touched. Coming near but being warned against touching them, they are only slightly less magical than the forbidden books in the Hogwart's library in the Harry Potter novels. The experience of working in these spaces is a sensory joy. The buildings and the reading spaces within are architectural beauties that show how in their periods of being built from the $16^{\text {th }}$ to $20^{\text {th }}$ centuries, their founders and patrons created spaces that are cathedrals to scholarship ensuring the survival of old books as physical objects waiting to be re-discovered by the reader. In these setting, 'reading' becomes such a close, intimate experience that it approaches a mystical encounter (Manguel 2010, p. 189).

Reflecting on this memory though, a counter train of thought emerges that tempers my ecstasy somewhat. I am mindful that in most cases, as indicated by the gender, class and race of the figures in the portraits on the walls of Duke Humphrey's Library, most women were not allowed into these 
hallowed spaces for hundreds of years. With Oxbridge, this access was not allowed until the $20^{\text {th }}$ century as Virginia Woolf eloquently describes in A Room of One's Own (1929). Trying to check a reference in Cambridge University Library, she is prevented by a librarian: "like a guardian angel barring the way with a flutter of black gown instead of white wings, a deprecating, silvery, kindly gentleman, who regretted in a low voice as he waved me back that ladies are only admitted to the library if accompanied by a Fellow of the College or furnished with a letter of introduction." (1991, p. 6).

Being a contemporary female traveller into these ancient places thereby acquires a more somber aspect. This awareness is reinforced by the fact that my subject of study is not the Classics, or canonical writers. Rather, I am researching the still sometimes maligned category of children's books, particularly movable books, which are not even considered literature, and on top of this including books written by non-famous children. All these provisos lend more of a political edge to my scholarly project.

\section{Endnotes}

${ }^{1}$ Please see the Hockliffe Project website at http://www.cts.dmu.ac.uk/hockliffe/. On occasion the site has software problems that prevent access.

${ }^{2}$ This virtual book is being developed in conjunction with the libraries at The Pennsylvania State University with student interns working for Sandra Stelts the curator of Rare Books and Manuscripts. This is in conjunction with my NEH digital start-up project "Learning a Playing: an interactive archive of $17^{\text {th }}-19^{\text {th }}$ century movable books for and by children (Beta at https://secureapps.libraries.psu.edu/content/flapbooks/).

\section{References}

Arendt, H. (1969) 'Introduction', in W. Benjamin, The Work of Art in the Age of Mechanical Reproduction. New York, Schocken.

Arizpe, E. \& Styles M. (2003) Children Reading Pictures. London, Routledge.

Donaldson-Randall, C. (2011) 'We Need to Talk About Granddad': Autoethnography in the Archives. MA thesis Archives and Records Management, University College, London.

Faden, E. (2007) 'Movables, movies, mobility: Nineteenth-century looking and reading', Early Popular Visual Culture 5, 1, 71-89.

Gibson, J. (1977) 'The theory of affordances', in R. Shaw \& J. Bransford (eds) Perceiving, Acting, and Knowing: Toward an Ecological Psychology. Hillsdale, NJ, Lawrence Erlbaum, pp. 6782.

Gracy, K. F. (2004) 'Documenting communities of practice: Making the case for archival ethnography’, Archival Science 4, 335-365.

Grenby, M.O. (2011) The Child Reader 1700-1840. Cambridge, Cambridge University Press.

Grenby, M. O. \& Immel, A. (2009) The Cambridge Companion to Children's Literature. Cambridge, Cambridge University Press.

Haining, P. (1979) Movable Books: An Illustrated History. London, New English Library. 
Hurst, C. (1995) Early Children's Books in the Bodleian Library. Oxford, Oxford University Press.

Immel, A. (2005) 'Frederick Lock's scrapbook: pattern in the pictures and writing in the margins', The Lion and the Unicorn 29, 65-76.

McGrath, L. (2002) This Magical Book: Movable Books for Children 1771-2001. Toronto, Toronto Public Library.

McKenzie, D.F. (1999) Bibliography and the Sociology of Texts. Cambridge, Cambridge University Press.

Manguel, A. (2010) A Reader on Reading. New Haven and London, Yale University Press.

Montanaro, A. (1993) Pop-up and Movable Books: A Bibliography. Metuchen, NJ, Scarecrow.

Muir, P. (1954) English children's books, 1600 to 1900. London, Batsford.

Murray, J. (1997) Hamlet on the Holodeck: The future of narrative in cyberspace. New York, Free Press.

O’Connell, S. (1999) The Popular Print in England. London, British Museum Press.

Paul, L. (2011) The Children's Book Business: Lessons from the Long Eighteenth Century. New

Reid-Walsh, J. (2008) 'Harlequin meets the Sims: A history of interactive narrative media for children and youth from early flap books to contemporary multimedia', in S. Livingstone \& K. Drotner (eds) International Handbook of Children, Media and Culture. London, Sage, pp. 71-86.

Reid-Walsh, J. (2012, in press) 'Activity and agency in historical "playable media", Children and Media.

Richards, M. (2000) Encyclopedia of Ephemera: A guide to the Fragmentary Documents of Everyday Life for the Collector, Curator, and Historian (ed. M. Twyman). New York, Routledge.

Woolf, V. (1991) A Room of One's Own. New York, Harcourt Brace \& Co.

\section{SOCR}

\section{Biographical Note}

Jacqueline Reid-Walsh is an associate professor in the College of Education at the Pennsylvania State University in the United States. She specializes in children's literature and women's studies and is fascinated by early children's books, especially movable books, digital media and girl culture. She has published a number of articles and book chapters in these areas. She has coauthored and co-edited several books including Researching Children's Popular Culture, Rutledge 2002 and is co-editor of Girlhood Studies: An Interdisciplinary Journal. She is presently engaged in a digital humanities project called "Learning as Playing" that is developing a scholarly website about early flap books that contains interactive, movable simulations that the viewer will be able to play with. 